\title{
Implementation of information technology: Issues connected with revision of business processes in transition
}

\author{
Henryk Sroka and Stanislaw Stanek \\ Institute of Management of the K. Adamiecki Academy of Economics \\ ul 1 Maja 50, 40-287 Katowice, POLAND \\ Phone+48(32) 598-421, FAX:48(32)586831 \\ Email:sroka@legato.ae.katowice.pl,stanek@legato.ae.katowice.pl
}

\begin{abstract}
Implementation of Information Technology is nowadays seen as a means, available to organizations, of improving their competitive position. However, the question arises, "What is it that makes improvement in one organization quick and successful but unsuccessful in another?" Analyzing the implementation requirements is crucial since it sets the initial direction and thereafter guides the evolution of the improvements. In this work we would like to present the suggested preconditions of, and our experience in, the implementation of innovative processes that are connected with the revision of the business processes in an organization in transition, with a special focus on the implementation of Information Technology. Soft system methodology requires that we perceive an organization as a whole. In organizational settings this kind of perception is strongly connected with the leader who is in a position to perceive the process of improvement in its relation to his vision, or concept. In this context it must be emphasized that technology now calls for general management leadership.
\end{abstract}

\section{Keywords}

Implementation of Information Technology, Implementation requirements, Revision of Business Processes, Organizations in transition, Organizational support, Innovative process, Supporting management decisions

\section{DETERMINING IMPLEMENTATION REQUIREMENTS}

Merely launching hardware and software at an existing organization problem does not necessarily cause this problem to be solved. Even after the introduction of new methodologies (Application Implementation Methodology, Business Process Reengineering/Redesign, Information Centre...), the implementation of improvement remains an art which turns ideas into money. In this work we will present the preconditions of, and 
our experiences in, the successful implementation of innovative processes which are connected with the revision of business processes in an organization in transition, with a special focus on the implementation of Information Technology. Questions like "Where are the main difficulties in the process of improvement implementation?", "Which are the factors that decide whether an improvement is successful or not?", "What is it that makes improvement in one organization quick and successful but unsuccessful in another?" are vital. Due to extensive investigation in which took part some major computer companies (IBM, Oracle, ICL, and others) we have a lot of empirical material to analyze. This material allows us to see a light in the dark cave.

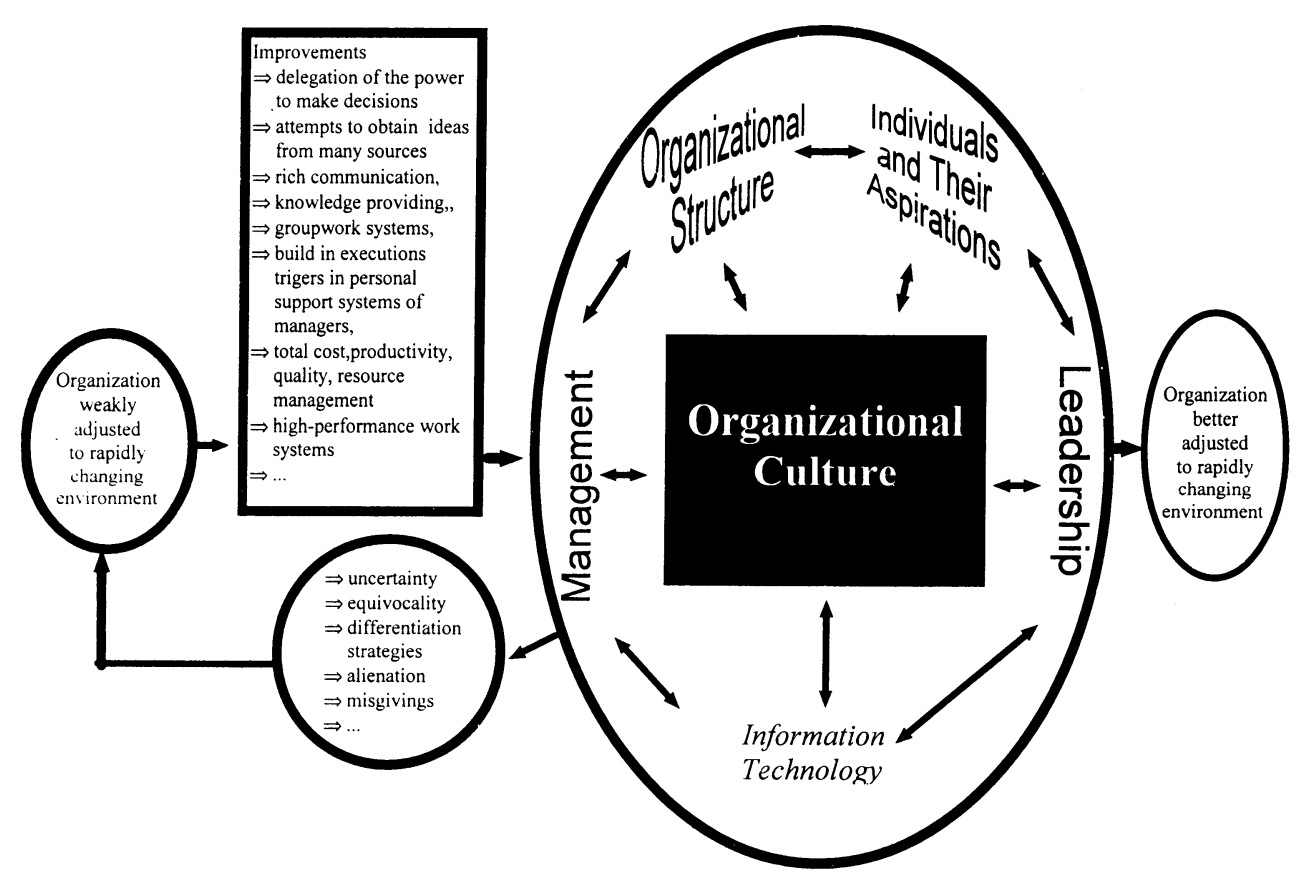

Figure 1 Dialectics of improvements in organizations

Let us start with the basic scheme given in Figure 1. Every organization performs a number of activities aimed at a better adaptation to the conditions imposed by external environment, according to the contemporary models of successful organizations. Unfortunately, many of them lack the necessary balance on two planes of interaction: the management - leadership one, and the other involving organization structure, Information Technology, and individuals and their aspirations. The organizational culture is the element which entails the inertia of the system. Moreover, accidental effects such as uncertainty, equivocality, and the differentiation 
of strategies of decision makers also come into play. In neutralizing these effects we may find helpful the principle of balance between the actions of leadership and management, adequate distributions of roles, and changes in the organization structure which are consistent with the Information Technology being implemented. The inertia of each organization is usually so great that without taking these preliminary measures the organization would quickly revert to the original state, or break up. Let us, therefore, move on to the implementation requirements.

\subsection{Allowing for the culture of an organization as a precondition of a successful innovative process}

Let us start with the old doctor's adage: "first of all, not to harm". De Lisi (1990) pointed out the interplay of forces of technology and culture which is at work in organizations. Major changes in technology, and then the difficulties in their adaptation into patterns of behaviour may cause a downfall (the lesson of the steel axe). Brook (1995) compared changes in the existing organizations with the volcano and a tree, and made a critical appraisal of the treatment of human resources. The observations made during the research had implications for recruitment, training, and career structures. By focusing on people rather than on technology, the main concern became, not the software's life cycle, but the employee's life cycle. A deeper understanding of the rapidly developing body of experience and knowledge about "cultural diversity" and management (Morden 1995), as well as opening our eyes to see, enable us to avoid serious mistakes. We have to learn the local norms, preferences, practices - perhaps even a new language or way of speaking - in order to fit in (Harris, 1985). Furthermore, the humanistic school which advises us to see information "as symbol rather than signal" is in agreement with this view (Symons, Waisham 1988).

\subsection{Enhancement of the leader's impact as the first precondition of a successful innovative process}

In an organization's reality the power of decision making rests with the decision maker (DM). On the one hand, DM is supported by experts (E) who only know certain aspects of the problem, but not its entirety, and on the other, the decision should be consistent with the general vision promoted by the leader (L). The leader's operations are well described by two words: vision and empowerment (D'Egidio, Moller 1992). These two are interrelated. The "vision" is the dream of the future we wish to create for our group (Matejka, Kurke, Gregory 1993). You need to have a vision in order to strengthen, inspire, and unite. The purpose of the organization - the goal it sets for itself - is contained in this vision. Information processes are the barometer of the effectiveness of leadership in an organization. Nowadays, as the competitive environment pushes an organization to its limits, there is an urgent need to establish the balance of power between the leader, the manager, and the experts. Huber (1988) concluded that the use of computers in the process of decision making and technologies supporting communication led to an increase of the influence of experts in organizational decision making. The results of Harvard's study (Kotler 1990) clearly indicated that in American enterprises there was much more traditional management than leadership. Empirical studies by Keely and Roure (1990) led to the conclusion that management is an important determinant of success, but its main contribution is through the 
implementation, and not through the formulation of the initial strategy. At this point we have to take into our account all the different kinds of problems an organization has to grapple with. If we distinguish: the rapidity of changes (the obsolescence of technology, the turbulence of the environment, strong competition), quantitative problems (multidimensionality, dispersion, the number of products and services), qualitative problems (complicated technology; legal, financial, accounting problems), and place, for simplicity, the roles of the leader, the decision maker, and the expert in three different dimensions, then the importance of each respective role is in proportion to the weight of the three groups of problems.

The topic of executive leadership in strategy research provides a tremendous opportunity for further development. We have very well developed and thoroughly tested models, and there is much room for further integration of leadership style in strategy formulation and implementation and in organizational performance (Nahavandi, Malekzadeh 1993, Taylor 1995).

\subsection{Success in Organizational Structure, Processes, and Personnel Development}

Implementation of Information Technology, along with the effective utilization of human resources, are now seen as the last remaining mechanism available to organizations to improve their competitive position (Leyland 1993, Morley \& Heraty 1995). But applying Information Technology calls for inductive thinking (Hamer \& Champy 1993): the ability to first recognize a powerful solution and then seek the problems it might solve; problems the company probably does not even known that it has. We have determined, too, that the condition being fulfilled that computer based communications systems are economically efficient at all levels of an organization, with tasks involving the processing of information (Huber 1984, Holt 1990), the interactions between the organization structure and its supporting technology could become so intense that maximum effectiveness would require their joint design. Recent studies have been sceptical of the importance of the internal structure in explaining a business company's performance. It is recommended however, that the U-form structure be used for small to medium sized firms, and the M-form structure for large firms (Weir 1995).

The case has been also argued for flattening the organization structure - so that it is no longer fragmented - the orientation of jobs or case teams around processes, and for making decisions (a task that managers formerly performed) by computer supported workers (Hamer Champy 1993, Young 1988). The novel approach to work design in a high technology environment includes the conception of high performance work systems. Designed to achieve the best "person - environment fit", high performance work teams are typically small groups of individuals (between 5 and 12) who work with the same facilitator, sponsor or coordinator. Normally, team members undergo training and development in brainstorming, effective interpersonal skills, problem solving, conflict handling, consensus building and decision making, as well as specific training designed to increase the organization's functional flexibility so that the team member has the ability to deploy acquired competence across a broader range of areas (Garavan, Moreley 1992; Moreley, Hearty 1995). 


\subsection{Orientation on leadership}

We have pointed out above the schema of the three interactions in an organization: leader (L), decision maker (DM), expert (E). What should be their roles in the context of Information Technology? Technology now requires general management leadership. Bob L. Martin (1995), President and CEO of Wal-Mart Stores, said "I think that CEOs increasingly recognize the impact that technology decisions have on their business and their corporate culture. As a result, they are becoming less comfortable delegating technology decisions to others. ... Chief information officers are in a critical role. CIOs who share the language and vision of the CEO and have a strong link with the business will help the CEO understand the business and organizational risk of new communications technologies." In speaking about the problems facing those who want to implement new information technology, it is important to stress the different level of complexity of the systems involved (see Figure 2). The new solutions that have been developed (e.g. EIS, DataWarehouse) enable us to formulate a more coherent strategy of organization support, and aid the leaders of an organization in transition.

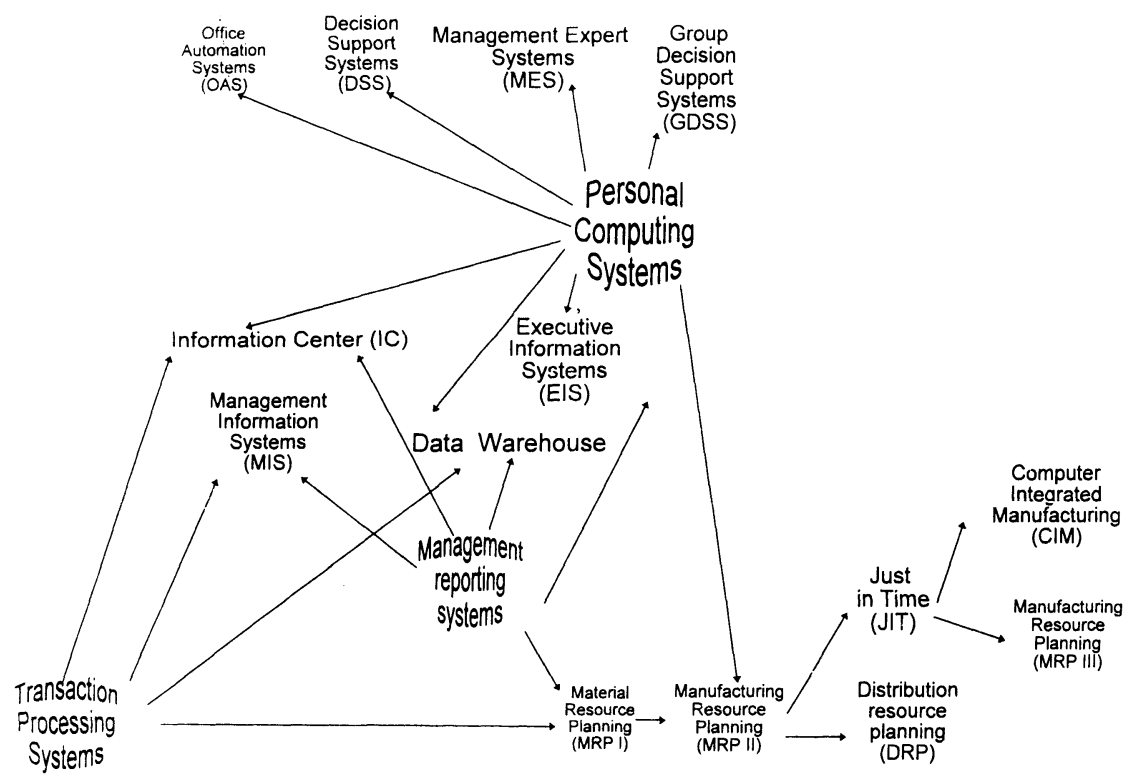

Figure 2 Dynamics in the development of management information systems

\subsection{Rich communication, group systems, triggers, and knowledge providing as means to avoid uncertainty, equivocality, and the differentiation of strategies of decision makers}

An organization which is in transition has to cope with many obstacles. Delegation of the power to make functional strategy decisions (Burgeois, Eisenhardt 1988), attempts to obtain many ideas from many sources (Kelly, Roure 1990), and the need to look for political 
alliances (Williams, Zmud 1990), can potentially escalate several well known shortcomings such as:

- uncertainty (in organizations where interdependence is high, uncoordinated actions of one department can force another department to change or adjust its actions or decisions accordingly)

- equivocality (managers from different departments may not share a common perspective and, thus, will have different interpretations of the same data, information, or events)

- differentiation of strategies (in transition there is a strong temptation to resolve known problems by informal, political means.

The remedy for these maladies is in using high technology that allows us (Daft, Lengel 1986, Latherwood, Dilla, Boland 1990) to:

- $\quad$ establish rich communication independent of place in which decision makers are staying at a given moment,

- focus our creativity on tasks such as generating ideas and actions, choosing alternatives, negotiating solutions by groupwork support systems,

- build execution triggers in managers' personal support systems,

- $\quad$ provide information along with the possibility to acquire knowledge (quick development of research on hypermedia in connection with decision support offers very interesting possibilities (RADA 1991).

\subsection{Aspiration to form a new culture of the organization in which the staff can feel more involved and which stands for the best service for clients}

Successful case study analysis (Stork, Compaq, ICI, Chrysler, Scandinavian Airlines etc.) pointed to the cultural change that had taken place. McGregor listed a number of characteristics observed in the operation of effective teams:

- The members listen to one another; every idea is given a hearing.

- The group is comfortable with disagreement, showing no signs of having to suppress conflict resulting in "open warfare", or the need for resolution through a vote.

- Decisions are reached by a kind of consensus in which it is clear that everybody is in general agreement and willing to go along.

- Successful organizations, wishing to develop their business, need to obtain many ideas from many different sources.

Inexpensive ways to obtain ideas should be developed, these ideas should be subsequently screened for strategic merit, and then a (relatively complete) management team should be assembled.

Knowledge has become the most crucial component in the struggle for competitiveness. Several years ago we reached a stage where the question had to be posed, "How can we build organizations in which continuous learning occurs?" (Senge 1990). Developing learning organizations requires new tools that enhance the leader's conceptual 
abilities, and foster communication and collaborative inquiry. The total quality movement has been the first wave in building learning organizations (Senge 1990b). To be able to make correct decisions and to stop redefining our objectives all too often, we need to be capable of distributing the limited improvement resources among these overlapping approaches: (1) total cost management, (2) total productivity management, (3) total quality management, (4) total resource management, (5) total technology management. There is a necessity of supporting the five methodologies (Ernest \& Young's technical report 93.001 lists the major tools used by each methodology). Acquiring the knowledge of joint venture partners through a process of organizational learning is now under consideration (Richter, Vettel 1995). Japan's experience in this area is of most significance for developing countries. Means should be found to spread knowledge internationally regardless of historical divisions.

\section{EVIDENCE ON THE IMPLEMENTATION OF INFORMATION TECHNOLOGY IN THE CONDITIONS OF TRANSFORMATION OF THE POLITICAL AND ECONOMIC SYSTEM}

We have been working on new ideas on supporting management with Information Technology (MIS, DSS) since late 70's. Since that time the Polish political and economic system has undergone substantial and consequential changes. Four stages can be distinguished:

\subsection{Centrally planned economy}

In the declining centrally planned economy of the early 80's we started by determining an executive's information needs in the largest Polish steel plant "Katowice". It was a methodological error: the problem solving process proved that those information needs were not easily determined in advance. When an immense body of data on the potential information needs of executives had been collected, using very sophisticated methods, the usefulness of the data stored in our data bases turned out to be illusory. In a centrally planned economy the managers tended to maintain a high level of hidden resources while negotiating a low level of plan targets, which was usually followed by effectively attaining the objectives or slightly exceeding the targets. As a consequence, it was rather hard to generate any interest in computer aided decision making.

\subsection{The illusion of a parametric economy}

With the unsuccessful attempt made in the years 1982-1985 in mind, we developed corporate models of RYFAMA, a small enterprise specializing in mining equipment. At that time in Poland's economy became prevalent the trend to switch from a centralized system to a parametric one, which inspired some managers with some interest in analyzing company's profit. Using the very friendly software for the ICL 4.50 (which was compatible with the ODRA 1305 computer produced in our country), e.g. statistical packages, PROSPER (profit simulation and risk), etc., we built an application which executives appeared to like, and which we then further developed in the desired direction indicated by the executives' reactions to the subsequent interim versions. At the time the global economic parameters 
were altered by the central government all too frequently and the persistent central interventions obscured the situation to such an extent that an informal (small) DSS seemed more appropriate. In general, an alliance of directors of enterprises with the organizations of workers would force the central government to give ground. The organization (i.e. RYFAMA) started to build up a vision of computerization which was not feasible, given the contemporary level of microcomputer technology and in view of the restrictions that were imposed on high technology by western countries and caused a delay in the introduction of Information Technology in Poland.

\subsection{Market oriented economy}

The transformation from the concept of a parametric economy to a market oriented one began in Poland in the 1990's. However, we lacked the necessary know-how and high Information Technology. We tried to test two approaches:

1 Much hope was placed in the development of knowledge-based systems. For example, the problem of labour valuation was solved by choosing several simple heuristics which controlled the user - system dialogue and the recording of the valuation procedures in a knowledge base. However, upon implementation, it turned out that, in these complicated and controversial areas, a simple knowledge-based system was too difficult for the users to accept. It was necessary to develop this prototype into a GDSS with a knowledge base module. After that, the system was introduced on a trial period of 18 months in many different business organizations (a large steel plant; civil engineering, electronics, clothing and foreign trade companies). During the test period of the labour valuation package, both the commercial system and the service approach were examined (cf. eg. Stanek, S. 1990a).

Later, encouraged by this success, we tried to build expert systems on the basis of a pre-prepared shell (cf. eg. Michalik, K. 1990, Sroka, H 1994). It was very easy to build prototypes of systems e.g. in students' MA projects, but developing these prototypes into products was very often a failure. Some of them, however, were at least partly successful, and have been further developed and updated, up to the present moment. An example of such an application could be the "Expert system for credit risk assessment". The first version of this system was created as a MSc project (Palonka, P. 1993). Later, it was handed over to the PKO S.A. bank for verification, but fell very short of the user's expectations. Most of all, the Credit Department of the bank complained about the incorrect allotment of point weights to particular factors, and the terminology used, but also requested the addition of a module to handle the creation of fund reserves. The bankers' comments received the careful consideration of the members of the special research group and set the direction for improvement and modifications (Stanek, S., Palonka, J., Palonka, P., 1994). The revised and enhanced version of the system was returned to the bank to undergo comprehensive tests on authentic data. A comparison of the results obtained by bank inspectors, who have analyzed the same cases, with those generated by the system revealed (cf. Palonka, P., 1995) that when evaluating credit risk involved with business entities that are not legally bound to produce detailed financial reports the system and the 
inspectors were agreed in $80 \%$ of cases. The bank's managers concluded that in the course of the tests the application had proved to function correctly, both in terms of the results generated and its technical reliability, and expressed much appreciation for its usefulness and functionality. At the request of the bank's management, the system was licensed to the bank as a handy tool in training bank personnel in credit risk assessment, and in rating the creditworthiness of applicants for loans.

Taking into account the difficulties in the maintenance of a DSS, we tried to utilize a DSS generator, developed as an extension of the Symphony package. Experience gained in the process of development indicated that the correct organization of the implementation process is just as important as the characteristics of the design itself.

Let us illustrate this with the example of a manufacturer of men's suits employing around 4,000 people, with a production capacity of 1 million suits per year and three major target markets: home market, western Europe, and the Soviet Union. In 1987 the activities of the existing electronic data processing unit in that large manufacturing business consisted mainly in maintaining data input systems (data on inventory of materials, fixed assets, work-in-progress, sales, direct work and use of materials) based on MERA 9150 data loggers (produced under licence from a British company REDIFON) with 22 data input stations. Those data were then processed using obsolete software in rented time on an Odra 1305 computer (ICL 1900 compatible third generation computer) owned by another company based in the vicinity. Toward the end of each year, as a large amount of data had been accumulated, computing would take a lot of time, causing delays in supplying the results to the Company's managers (it was not unusual for the Managing Director to pay penalties for failing to turn in the company's statistics to the Central Statistical Office on time). The Financial Director, to whom the EDP Section reported, was willing to start collaboration, yet he insisted on instant effects even before deciding on any purchases.

We decided to offer them a three months' lease of an Academy owned XT microcomputer so that they could test the capabilities of IBM PC microcomputers, along with the software generator we had been working on. It turned out that all the data that had formerly been batch processed by a mainframe computer could just as well be processed on a day-to-day basis by an XT microcomputer connected to the multi-station MERA 9150 data logger. When the lease period expired, the company had already become the owner of several IBM PC AT computers. Having started cooperation with the Financial Director as well as other section managers (EDP, Planning, Finance, Wages \& Salaries, Sales), we were able to analyze varied partly structured decision making problems and immediately generate adequate computing models using our decision support systems generator (cf. e.g. Sroka, H. and Stanek, S. 1989; Stanek, S. 1990b).

As to the breakdown of decision support systems into those oriented on data, models, or of logical nature, the principle of disproportional gradation of the difficulty level in the implementation of systems was verified true (cf. e.g. Alter, S 1980, Camussone, P 1985, Stanek, S. 1994b). The data procurement system was the easy part. An initiative to found this sort of system may well come from an EDP department or an information centre staff, who know the company's information 
needs, are aware of its possibilities in terms of hardware and software, and are acquainted with decision support systems. As decision makers and experts become involved, there arises the need to analyze the data. At the next stage of development a model-oriented decision support system - we thus faced a qualitative barrier. Very little of previous experience could be directly transferred and applied. At this point it was the decision makers who had to take the lead, any attempt to shift the initiative away from them or impose any solutions would result in opposition. In each case the scope, time and form of support had to be individually determined by the particular decision maker. The computer was only one of the many items his view of the organization encompassed. With every single problem, however, advice had to be provided concerning the choice and application of quantitative techniques, their allocation depending not solely on the type of problem but also on the data, time and resources available (contribution of the Information Centre).

The transition toward logical models constitutes another substantial qualitative change. The pivotal problem was usually the necessity to allow for a great number of additional conditions when moving from concept to practical implementation. Further development of the company's information system and its better adaptation into global competition required increased capital spending (computer networks, increasing computing power, fourth generation tools, intensive staff training). In spite of a slump on the Russian market (initially, large outstanding payments, and subsequently reduction of orders from a market that used to account for as much as $1 / 3$ of the company's sales), the company adopted a strategy aimed at retaining its position.

\subsection{Adaptation into global competition}

The next step in the transformation of our economy is the necessity of a better adaptation of organizations into global competition. With little alternative to domestic sources of financing, it is hoped that the privatization of the former state-owned enterprises (SOEs) will be accompanied by a growth in foreign investment, particularly through joint ventures. Foreign capital cannot only underwrite the modernization of the industrial base, it can be the mechanism of introducing modern business practices and technologies (Ferris, Joshi, Makhija 1995). A more global view of using Information Technology is essential.

The most difficult problems are connected with coal mining. Coal mines are characterized by huge differences in the cost of production; in some of them this cost happens to be even several times higher or lower than the average. A political decision was taken to the effect that a gradual transfer of resources between mines would take place. Obviously, this will require a powerful support system. The largest Polish software house, the Centre of Information Systems for Mining Industry (COIG), is responsible for the construction of information systems. As indicated by the experience in the implementation of decision support systems discussed above, the work started with the formulation of the concept of a system oriented on input of data.There is a plan to build DataWarehouses to link all the different systems working for each specific coal mine. As a first step, a prototype of EIS was created by graduate students of our Academy working for the COIG, using SAS software and based on data and guidelines provided by the COIG analysts (cf. Koszowski, Z. 1995). 
The prototype of the DataWarehouse is now in the process of construction - SAS and Oracle software is used - and will be distributed depending on the needs of the specific coal mines. Another example of our activities will be the implementation of Information Technology for health care service, developed in cooperation with OPTIMUS, the largest Polish computer company, and for banking.

\section{CONCLUSIONS}

In view of the above discussion, it seems that the following conclusions can be drawn:

1. Where decision making processes are centralized the introduction of computer based support systems may facilitate the consolidation of existing relations, resulting in inefficient operation, which can pose a serious threat to an organization operating in a competitive environment.

2. Providing computer support for single, isolated decision making processes may aggravate conflicts, increase disagreement about the strategic goals, and induce informal political actions, with only slight, and short term, beneficial effect on the company's global performance indicators.

3. Ensuring a proper balance between rich support, teaching/learning and imparting information in a cooperation oriented environment may bring about qualitative changes in the process of managing the organization, providing the framework for inspiring actions (empowerment) on which the leader's impact is based.

4. The high rate of development of information technology - including the technology of knowledge base systems, graphical work environment, multimedia solutions, groupwork support systems, etc. - is an important factor in eliminating such threats as mutual uncertainty of the managers, equivocality of information, and the differentiation of decision makers' strategies.

5. It is our recommendation that the basic elements of the concept of decision support systems insisting on orientation on an individual decision maker be further developed towards focus on the decision maker within, and as part of, the organization, which will make it necessary to incorporate the design of Information Technology in the design of the organization structure itself.

\section{ACKNOWLEDGEMENTS}

In the present work have been used the findings of the following Central research programs:

- MR.I.30 "Development of methods of system analysis and their application in national economy" (Rozwój method analizy systemowej oraz ich zastosowanie w gospodarce narodowej): 1980-1985;

- CPBP 02.15 "Development of system research and its top-priority applications" (Rozwój badañ systemowych i ich priorytetowych zastosowañ): 1986-1990;

- RPBR.0.2 "Selected Applications of Information Systems" (Wybrane zastosowania informatyki): 1987-1990;

Grant 828/91 "Management Information Systems in Support of Decision making in an Organization in a Market Economy" (Informatyczne wspomaganie decyzji kierowniczych w organizacji w warunkach gospodarki rynkowej): 1990-1995. 


\section{REFERENCES}

Alter, S.L. (1980) Decision Support Systems: Current Practice and Continuing Challenge, Addison Wesley

Brook, E.C. (1995) Volcanoes and trees: identifying a suitable working environment', Management. Decision, 33, 5-11

Camussone, P.F. (1985) I Sistemi Informativi Direzionali, Industrie Pirelli Spa, Milano 46-60

D'Egidio, F. and MOLLER, C. (1992) Vision \& Leadership, Franco Angeli.

DeLisi, P. (1990) Lessons from the Steel Axe: Culture, Technology, and Organizational Change, Sloan Management Review, 83, 83-93

Ferris, S., Joshi, P. and Makhija, K. (1995) Valuing an East European Company", Long Range Planning, 28, No 6, 48-60

Garavan, T. and Morley, M. (1992)Organization change and development: introducing flexible working groups in a high technology environment", in Winstanley, D. and Woodhall, J. (Eds.) 'Case Studies in Personnel, Institute of Personnel Management, 1992

Hammer, M. and Champy, J. (1993) Re-engineering the corporation. A manifesto for business revolution, Nicholas Brealey Pub.

Harris, P.R. (1985) Management in transition, Jossey-Bass, 305-322

Holt, C.C. (1990) Conceptual environment for Organization Support Systems: Design and Use of Information Technology in Organizations, in Vecsenyi, J., Sol H.G. (Ed.), Environments for Supporting Decision Processes, Proceeding of IFIP WG 8.3 Working Conference on Organizational Decision Support Systems, June 1990

Huber, G.P. (1984) The nature and design of postindustrial organizations, Management Science, 30, No. 8, 928-951.

Huber, G.P. (1988) Effects of Decision and Communication Support Technologies on Organizational Decision Processes and Structures, in Lee, R.M., McCosh A., Migliarese,P (Ed.), Organizational Decision Support Systems, Proceeding of IFIP WG 8.3 Working Conference on Organizational Decision Support Systems, June 1988

Keely, R. and Roure, J. (1990) Management, strategy and industry structure as influences on the success of new firms: a structural model', Management. Science, 36, No.10, 1256-1267

Koszowski, Z. (1995) Koncepcja wykorzystania systemu SAS we wspomaganiu planowania ob $\geq_{i}$ enia kadr $\pi$ przodków w kopalniach wêgla kamiennego, (A Concept Of Using The SAS System In Support Of Planning The Working Face Staffing In Coal Mines), II Konferencja U ¿ytkowników Systemu SAS w Polsce (II Polish Users of SAS System Conference), Warszawa, 1995

Kotler, J.P. (1990) A Force for Change, New York

Leyland, V. (1993) Electronic data interchange. A management view, Prentice Hall, 1993

Matejka, K., Kurke, B. and Gregory, B. (1993) Mission Impossible? Designing a Great Mission Statement to Ignite Your Plans, Management Decision, 31 No. 4, 34-37

Michalik, K. (1990) Prototypowy system ekspercki, w H. Sroka (red.) Reprezentacja $i$ modelowanie $z \geq 0$ ¿onych i nieustrukturalizowanych decyzji (Expert System Prototype in $\mathrm{H}$. Sroka's (ed.) Representation And Modelling Of Complex And Unstructured Decisions), AE Katowice, 76-86

Morden, T. (1995) International culture and management, Management Decision, 33 No.2, $16-21$ 
Morley, M. and Hearty, N. (1995) The high performance organization: developing teamwork where it counts, Management Decision., 33 No.2, 56-63

Morley, M. and Hearty, N. (1995) The high performance organization: developing teamwork where it counts', Management. Decision, 33, No. 2, 56-63

Nahavandi, A. (1993) Leader style in strategy and organizational performance: an integrative framework, Journal of Management St., 30:3, 405-425.

Perspectives (1995) The end of delegation? Information Technology and the CEO, Harvard Business Rev., September-October, 161-172

Palonka, P. (1994) System ekspertowy do oceny ryzyka kredytowego (Expert System for credit risk assessment), a thesis presented in part fulfilment of the requirements of the MSc degree at AE Katowice

Palonka, P. (1995) System ekspertowy do oceny ryzyka kredytowego, w Sroka, H. oraz Stanek, S. (red.): Inteligentne systemy wspomagania decyzji w zarz $\pi$ dzaniu (Expert System For Credit Risk Assessment, in Sroka, H. and Stanek, S. (ed.): Intelligent Decision Support Systems in Management), AE Katowice, 251-256

Rada, R. (1991): Hypertext and paper: a special synergy, International Journal of Information Management, March

Senge, P. (1990b) The leader's New Work: Building Learning Organizations, Sloan Management Review, Fall , 7-23

Senge, P. (1990) The Fifth Discipline: The Art and Practice of the Learning Organization, New York: Doubleday/Currency

Sroka, H. and Stanek, S. (1989) Anwendung spezieller DDS - Generatoren fur die Entscheidungsfindung, Konferenzbeitrag zur Tagung 'Rechneruterstutzer Arbeitsplatz des Okonomen', Sektion Wirtschaftsinformatic, Hochschule fur Okonomie 'Bruno Leuschner' Berlin, 30-35

Sroka, H. (1994) Systemy ekspertowe (Expert Systems), AE Katowice

Stanek, S. (1990a) SWD dla wartoúciowania pracy, w H. Sroka (red.) Reprezentacja i modelowanie $z \geq o_{¿}$ onych $i$ nieustrukturalizowanych decyzji (Decision Support System For Work Valuation, in H. Sroka (ed.) Representation And Modelling Of Complex And Unstructured Decisions), AE Katowice, 59-76

Stanek, S. (1990b) Generator SWD "Eureka", w H. Sroka (red.) Reprezentacja $i$ modelowanie $z \geq 0$ ¿onych $i$ nieustrukturalizowanych decyzji (The "Eureka": A Decision Support Systems Generator, in H. Sroka (ed.) Representation And Modelling Of Complex And Unstructured Decisions), AE Katowice, 87-97

Stanek, S., Palonka, J. and Palonka, P. (1994a) System ekspertowy do oceny ryzyka kredytowego (Expert System For Credit Risk Assessment), Grant 828 Technical Report, AE Katowice

Stanek, S. (1994b) Systemy bazuj $\pi$ ce na wiedzy w formu $\geq$ owaniu strategii organizacji (Knowledge-Based Systems In Determining An Organization's Strategy), AE Katowice Symons, V. and Walsham, G. (1988) The Evaluation of information systems: a critique, Journal of Applied Systems Analysis, 15, 119-132

Taylor, B. (1995) The new strategic leadership - driving change, getting results', Long Range Planning, 28, No.5, 71-81.

Weir, C. (1995) Organizational structure and corporate performance: an analysis of medium and large UK firms, Management Decision, 33 No. 1, 24-32. 
Young, L. (1988) Worker participation Support Systems: A missing link in Organizational Computer Support?, in Lee, R.M., McCosh A., Migliarese, P. (Ed.), Organizational Decision Support Systems, Proceeding of IFIP WG 8.3 Working Conference on Organizational Decision Support Systems, June.

\section{BIOGRAPHY}

Henryk Sroka is Professor of Management and Business Informatics at the Academy of Economics in Katowice, Poland. He is the author of more than 250 articles, monographs, projects, case studies and 15 books (including Organizational DSS" - 1986, Representation and Modelling of Complex and Unstructured Decisions" - 1990, Expert Systems in Finance and Banking" - 1994, "Intelligent DSS in Management" -1995). Professor H. Sroka studied at the University of Wroclaw, Osaka University, and Tohoku University. He earned his research and honours degrees and titles including $\mathrm{PhD}$, assistant, associate and full professor at the Academy of Economics in Katowice. He has held many positions in the field of information systems (Corporate Computer Centres, Polish Academy of Sciences, the Technical University of Silesia, Management and Business Informatics Colleges in Bielsko and Katowice) such as developer, manager, educator and researcher. He has been president of the organization committee of an annual scientific conference on DSS in Poland since 1980 , member of editorial review boards in several conferences and scientific institutions and societies, visiting professor of Japanese and European universities.

Stanislaw Stanek is Associate Professor of Management and Business Informatics at the Academy of Economics in Katowice, Poland. He embarked on his academic career after 10 years of research work - of those 4 as director of a research project team -,in the Institute of Management of Polish Academy of Sciences, and in industry (BZPO Bytom Co.). He received his MSc degree in Applied Mathematics from the Technical University of Wroclaw and his PhD in Economics from the Central Business School (Szkola Glówna Handlowa) in Warsaw. He has held many positions in the field of information systems such as developer, manager, educator and researcher. He is a computer consultant specializing in MIS, GDSS, EIS and DataWarehouse. He took part in many research projects (Polish Goverment Central Research Programs, TEMPUS Projects, grants). He has been member of the organization committee of an annual scientific conference on DSS in Poland, and member of an editorial review board. He is the auhor of more than 100 articles, monographs, projects, case studies and 5 books (including "Representation and Modeling of Complex and Unstructured Decisions" - 1990, "Knowledge Based Systems in Formulating Organizational Strategies" 1994, "Inteligent DSS in Management" -1995). 